\title{
Efeitos de doses de nitrogênio na produção de leite de vacas em pastagem de coast-cross ${ }^{(1)}$
}

\author{
Maurilio José Alvim ${ }^{(2)}$ e Milton de Andrade Botrel(2)
}

\begin{abstract}
Resumo - O objetivo do trabalho consistiu em avaliar os efeitos de três doses de nitrogênio $(\mathrm{N}), 100$, 250 e $400 \mathrm{~kg} / \mathrm{ha} / \mathrm{ano}$, aplicadas em pastagem de coast-cross (Cynodon dactylon (L.) Pers.) sobre a produção de leite em duas lactações de vacas da raça Holandesa. A pastagem foi irrigada na seca e manejada sob pastejo rotativo. O delineamento experimental foi o de blocos ao acaso, em parcelas subdividas (nas parcelas, doses de N; nas subparcelas, fases da lactação), com oito animais por tratamento e duas repetições de área. Os teores de proteína bruta do pasto foram semelhantes $(\mathrm{P}>0,05)$ entre os tratamentos. A taxa de lotação da pastagem foi inferior $(\mathrm{P}<0,05)$ na menor dose de $\mathrm{N}$. Não foi observada diferença $(\mathrm{P}>0,05)$ na produção diária de leite por animal. As produções de leite por área foram mais elevadas $(\mathrm{P}<0,05)$ nas duas maiores doses de $\mathrm{N}$. A aplicação de $100 \mathrm{~kg} / \mathrm{ha} /$ ano de $\mathrm{N}$ foi a que proporcionou maior quantidade de leite por quilograma de $\mathrm{N}$.
\end{abstract}

Termos para indexação: adubação nitrogenada, gramíneas, manejo de pastagem, alimentação animal, rendimento leiteiro

Effects of levels of nitrogen on the milk production of cows in coast-cross pasture

Abstract - The purpose of this work was to evaluate the effects of three levels of nitrogen $(\mathrm{N}), 100,250$ and $400 \mathrm{~kg} / \mathrm{ha} /$ year, applied in coast-cross (Cynodon dactylon (L.) Pers.) pasture on the milk production of Holstein cows during two lactation periods. The pasture was irrigated in dry season and used by rotational grazing. The experimental design was in randomized blocks, in split plots (plot $=$ level of $\mathrm{N}$; split plot $=$ period of lactation), with two pasture replications and eight cows per treatment. The crude protein contents were similar $(\mathrm{P}>0.05)$ in the treatments. The stoking rates of pasture was lowest $(\mathrm{P}<0.05)$ in the lowest level of $\mathrm{N}$. The milk production per day and per animal were similar $(\mathrm{P}<0.05)$ in the treatments. The milk productions per area were higher $(\mathrm{P}<0.05)$ in two highest levels of $\mathrm{N}$. The milk production per $\mathrm{kg}$ of $\mathrm{N}$ applied was highest in the level of $100 \mathrm{~kg} / \mathrm{ha} / \mathrm{year}$.

Index terms: nitrogen fertilizers, grasses, grassland management, animal feeding, milk yield.

\section{Introdução}

Atualmente, tem-se observado uma tendência de maior especialização dos sistemas de produção de leite do Brasil, especialmente nas Regiões Sudeste e Sul, onde se encontram as principais bacias leiteiras do País (Botrel et al., 1994). Nesses sistemas são usa-

\footnotetext{
(1)Aceito para publicação em 13 de junho de 2000 .

(2)Embrapa-Centro Nacional de Pesquisa de Gado de Leite, Rua Eugênio do Nascimento, 610, Dom Bosco, CEP 36038-330 Juiz de Fora, MG. Bolsista do CNPq E-mail: alvim@cnpgl.embrapa.br, mbotrel@cnpgl.embrapa.br
}

dos animais de elevado potencial genético para produção de leite, mantidos em confinamento, recebendo dieta de alto valor nutritivo, à base de concentrados e forragens conservadas, como silagens e fenos. Entretanto, os resultados da pesquisa de Vilela et al. (1996) revelaram que esse sistema de alimentação de vacas em lactação é de custo mais elevado, quando comparado com o pastejo rotativo em coast-cross (Cynodon dactylon (L.) Pers).

Stobbs (1976) e Martinez et al. (1980) mostraram que o manejo adequado de pastagens constituídas por espécies tropicais pode resultar em elevadas produções de leite. Segundo Cowan (1990), a produção de leite de vacas em pastagem de boa qualidade pode 
atingir até $4.500 \mathrm{~kg} / \mathrm{vaca} /$ lactação, sem recorrer ao uso de concentrados.

O coast-cross é uma gramínea que apresenta características forrageiras desejáveis, como elevada produção de matéria seca, boa relação folha/colmo e alto valor nutritivo (Herrera, 1983). Quando usado adequadamente, é recomendado para alimentar vacas de elevado padrão genético (Infante, 1983), apresentando alta capacidade de suporte, com reflexos positivos sobre a produção de leite (Trujillo, 1983).

$\mathrm{O}$ nitrogênio $(\mathrm{N})$ é o principal nutriente para o crescimento das forrageiras, elevando a qualidade da forragem disponível para o animal e a capacidade de suporte da pastagem e, conseqüentemente, aumentando a produção de leite por área. Herrera et al. (1986) e Alvim et al. (1998) registraram, em condições de corte, elevada produção de forragem do coastcross, com alto valor nutritivo, em razão da adubação nitrogenada. Sob pastejo, Vilela et al. (1996) e Alvim et al. (1997) registraram elevadas produções de leite com vacas da raça Holandesa em pastagem de coast-cross, adubada com $350 \mathrm{~kg} / \mathrm{ha} /$ ano de $\mathrm{N}$. No entanto, esse nível de adubação nitrogenada contribuiu de forma expressiva na elevação dos custos da produção do leite, apesar de a alimentação das vacas a pasto ter sido mais econômica do que a das vacas em confinamento.

O objetivo deste trabalho foi avaliar os efeitos de doses de $\mathrm{N}$ em pastagem de coast-cross, sobre a produção de leite de vacas da raça Holandesa.

\section{Material e Métodos}

O trabalho consistiu em avaliar, durante duas lactações compreendidas entre os períodos de 14 de janeiro a 14 de novembro de 1997 e 6 de janeiro a 6 de novembro de 1998 (304 dias/período), a produção de leite de vacas da raça Holandesa mantidas em pastagem de coast-cross, recebendo a aplicação de três doses de $\mathrm{N}$, que consistiram os tratamentos: $\mathrm{A}=100 ; \mathrm{B}=250 \mathrm{e} \mathrm{C}=400 \mathrm{~kg} / \mathrm{ha} / \mathrm{ano}$. Em 304 dias (período experimental), essas doses de $\mathrm{N}$ corresponderam às aplicações de 85,210 e $335 \mathrm{~kg} / \mathrm{ha}$

O experimento foi conduzido no campo experimental da Embrapa-Centro Nacional de Pesquisa de Gado de Leite, situado em Coronel Pacheco, MG, $\left(21^{\circ} 33\right.$ '22" de latitude Sul e $43^{\circ} 6^{\prime} 15^{\prime \prime}$ de longitude Oeste). O clima da região é do tipo Cwa (mesotérmico), definido como temperado chuvoso no verão e com inverno seco. A precipitação média anual está ao redor de $1.500 \mathrm{~mm}$, distribuídos irregularmente, com a precipitação da época da seca (maio a setembro) correspondendo a $200 \mathrm{~mm}$, aproximadamente.
Em cada lactação foram usadas 24 vacas Holandesas PO e PC (oito por tratamento), com potencial de produção de leite de aproximadamente $6.000 \mathrm{~kg} /$ lactação Os animais eram da segunda, terceira ou quarta lactação, e, no início das avaliações, estavam com cerca de 20 a 30 dias pós-parto.

A pastagem de coast-cross localizava-se em área plana de várzea, em solo classificado como Aluvial eutrófico, que, ao início das avaliações, apresentava as seguintes características químicas: $\mathrm{pH}$ em água $(1: 2,5) 6,1$; $\mathrm{P}, 19,4 \mathrm{mg} / \mathrm{dm}^{3} ; \mathrm{K}, 96,2 \mathrm{mg} / \mathrm{dm}^{3} ; \mathrm{Al}, 0,2 \mathrm{cmol}_{\mathrm{c}} / \mathrm{dm}^{3}$; $\mathrm{Ca}, 4,3 \mathrm{cmol}_{\mathrm{c}} / \mathrm{dm}^{3} ; \mathrm{Mg}, 1,9 \mathrm{cmol}_{\mathrm{c}} / \mathrm{dm}^{3} ; \mathrm{MO}, 2,9 \mathrm{mg} / \mathrm{dm}^{3}$.

De junho a outubro, a pastagem foi irrigada por aspersão a cada 15 dias, com a lâmina de água correspondendo a $35-45 \mathrm{~mm}$

Além do $\mathrm{N}$, a pastagem foi adubada com $\mathrm{K}$, numa relação $\mathrm{N} / \mathrm{K}_{2} \mathrm{O}$ igual a um, e $\mathrm{P}$, na dose de $80 \mathrm{~kg} / \mathrm{ha} / \mathrm{ano}$. Os fertilizantes foram misturados e fracionados em dez aplicações, distribuídos em superfície sempre após a saída dos animais dos piquetes.

A área total da pastagem foi de seis hectares, divididos em duas repetições/tratamento, sendo a área de cada repetição igual a um hectare. Para cada repetição foram usadas quatro vacas experimentais, com média de peso de 597 e $606 \mathrm{~kg} / \mathrm{vaca}$, no primeiro e segundo períodos experimentais, respectivamente

A área de cada repetição foi dividida por cerca elétrica em 33 piquetes de $300 \mathrm{~m}^{2}$, no período de maio a setembro (época da seca e de baixa temperatura), e em 25 piquetes de $400 \mathrm{~m}^{2}$, no período de outubro a abril (época das chuvas e de temperatura elevada). Adotou-se o pastejo rotativo, sempre com um dia de ocupação do piquete e 32 e 24 dias de descanso nos períodos da seca e das chuvas, respectivamente. A pressão de pastejo adotada foi próxima de $6 \%$ Para manter essa pressão de pastejo ao longo do ano, adotou-se o sistema "put and take", usando vacas extras em lactação e de potencial produtivo semelhante ao das vacas experimentais

Foram estimadas semanalmente, antes e após o pastejo, a forragem disponível e a residual na pastagem (Tabela 1). Essa estimativa se baseou na quantidade de forragem cortada, antes (forragem disponível) e após (forragem residual) o pastejo, a $8 \mathrm{~cm}$ acima do nível do solo, e retirada do interior de um quadrado de um metro de lado, lançado ao acaso por três vezes em cada piquete. Toda vegetação existente abaixo do extrato de $8 \mathrm{~cm}$ foi desconsiderada Parte da forragem colhida foi levada ao laboratório para se estimar a qualidade da forragem, com base nos teores de proteína bruta e de digestibilidade in vitro da matéria seca. A estimativa do consumo diário de matéria seca de coast-cross pelos animais no pasto foi obtida pelo desa- 
Tabela 1. Disponibilidade de matéria seca, matéria seca residual e relação colmo/folha na pastagem de coast-cross, fertilizada com três doses de nitrogênio ${ }^{(1)}$

\begin{tabular}{|c|c|c|c|}
\hline \multirow[t]{2}{*}{ Época } & \multicolumn{3}{|c|}{ Doses de N (kg/ha/ano) } \\
\hline & 100 & 250 & 400 \\
\hline & \multicolumn{3}{|c|}{ Matéria seca disponível (kg/ha) } \\
\hline Chuvas & 6.008 & 6.721 & 6.813 \\
\hline \multirow[t]{2}{*}{ Seca } & 2.523 & 3.189 & 3.398 \\
\hline & \multicolumn{3}{|c|}{ Matéria seca residual $(\mathrm{kg} / \mathrm{ha})$} \\
\hline Chuvas & 3.609 & 4.164 & 4.201 \\
\hline \multirow[t]{2}{*}{ Seca } & 1.278 & 1.801 & 1.937 \\
\hline & \multicolumn{3}{|c|}{$\begin{array}{c}\text { Relação colmo/folha, } \\
\text { na matéria seca disponível }\end{array}$} \\
\hline Chuvas & 0,70 & 0,74 & 0,66 \\
\hline Seca & 1,39 & 1,40 & 1,27 \\
\hline
\end{tabular}

parecimento da forragem na pastagem através do pastejo, calculado pela diferença entre as quantidades de matéria seca disponível e residual do piquete, dividida pela taxa de lotação momentânea da pastagem (vacas experimentais e vacas extras), conforme critério adotado por Alvim et al. (1997)

O período compreendido entre 15 de novembro de 1997 a 5 de janeiro de 1998 foi considerado período não-experimental. Durante este período, foram selecionadas as vacas experimentais para dar início às avaliações do período seguinte. Neste período, a pastagem foi manejada conforme o critério adotado nos dois períodos experimentais, usando-se vacas em fase final de lactação

As vacas receberam, diariamente, 9, 6 e $3 \mathrm{~kg}$ de concentrado, respectivamente nos primeiros 100 dias, entre 100 e 200 dias e nos últimos 104 dias da lactação, sendo metade fornecida no momento da primeira ordenha e metade durante a segunda ordenha. O concentrado apresentava $24 \%$ de proteína bruta e $84 \%$ de nutrientes digestíveis totais, sendo constituído de: $50 \%$ de fubá de milho, $21,7 \%$ de farelo de soja, $15 \%$ de soja integral, $5 \%$ de protenose (glúten de milho com $60 \%$ de proteína bruta), 3\% de melaço, $2,2 \%$ de calcário, $1,2 \%$ de bicarbonato de sódio, $0,5 \%$ de sal comum, $0,5 \%$ de vitamina ADE, $0,5 \%$ de microminerais e $0,4 \%$ de óxido de magnésio.

As vacas tiveram acesso livre à sombra, bebedouro e cocho com sal mineral. Apesar de apresentarem cios, não foram inseminadas durante o período experimental

As análises estatísticas foram feitas da seguinte maneira: as produções diárias de leite por animal foram analisadas por fase da lactação (100, 100 e 104 dias cada uma), conforme o delineamento de blocos ao acaso, com parcelas divididas; nas parcelas, foram alocadas as três doses de N, e nas subparcelas, as três fases de lactação. As demais análises foram feitas de acordo com o delineamento em blocos ao acaso. Nas produções diárias de leite por animal, a unidade de observação foi representada pela vaca; na produção de leite por área e nas variáveis relativas à qualidade do pasto, foram consideradas duas repetições de pastagem.

\section{Resultados e Discussão}

$\mathrm{Na}$ época da seca, os teores médios de proteína bruta e de digestibilidade in vitro da matéria seca da forragem disponível para os animais foram menores $(\mathrm{P}<0,05)$ em relação aos da época das chuvas, caracterizando, assim, maior qualidade do pasto nesta época do ano. Entre tratamentos, essas variáveis foram semelhantes $(\mathrm{P}>0,05)$ (Tabela 2). Apesar de os teores de proteína bruta e de digestibilidade in vitro da matéria seca obtidos neste trabalho serem considerados elevados em gramíneas tropicais e, portanto, adequados para se conseguir altas produções de leite (Davison, 1990), os resultados indicam que, mesmo com irrigação na época da seca, doses mais elevadas de $\mathrm{N}$ não foram capazes de manter a elevada qualidade da forragem ao longo do ano. Possivelmente, isso se deve à existência de fatores ambientais adversos ao crescimento da forrageira durante a época da seca. Apesar da irrigação realizada, nesta época ocorreu baixa temperatura com pouca luminosidade,

Tabela 2. Teores de proteína bruta e de digestibilidade in vitro da matéria seca na pastagem de coast-cross em razão de doses de nitrogênio ${ }^{(1)}$

\begin{tabular}{llcc}
\hline Época & \multicolumn{3}{c}{ Doses de N (kg/ha/ano) } \\
\cline { 2 - 4 } & 100 & 250 & 400 \\
\hline \multirow{3}{*}{ Chuvas } & $17,6 \mathrm{aA}$ & $17,4 \mathrm{aA}$ & $17,0 \mathrm{aA}$ \\
Seca & $12,9 \mathrm{aB}$ & $13,3 \mathrm{aB}$ & $13,3 \mathrm{aB}$ \\
\hline Média & $15,2 \mathrm{a}$ & $15,3 \mathrm{a}$ & $15,1 \mathrm{a}$ \\
\hline \multirow{3}{*}{ Chuvas } & Digestibilidade in vitro da matéria seca $(\%)$ \\
Seca & $66,1 \mathrm{aA}$ & $70,2 \mathrm{aA}$ & $68,0 \mathrm{aA}$ \\
Média & $55,1 \mathrm{bA}$ & $57,3 \mathrm{aB}$ & $58,4 \mathrm{aB}$ \\
\hline
\end{tabular}

(1)Média de dois períodos de avaliação, de 304 dias cada um; médias seguidas da mesma letra, minúscula na linha e maiúscula na coluna, não diferem entre si, pelo teste de Tukey a 5\% de probabilidade. 
reduzindo a disponibilidade de forragem para os animais em pastejo e favorecendo a relação colmo/folha na pastagem, independentemente da dose de $\mathrm{N}$ aplicada (Tabela 1). Na época das chuvas ou de temperatura mais elevada, o consumo de matéria seca proveniente do pasto foi maior, mesmo quando os animais receberam maior quantidade de concentrado (Tabela 3). Por outro lado, as doses de $\mathrm{N}$ aplicadas não modificaram a qualidade da forragem do coast-cross. Com isso, as produções médias individuais de leite, as produções de leite total por lactação e as produções médias de leite, relativas a todo o período experimental, não diferiram $(\mathrm{P}>0,05)$ entre os tratamentos avaliados. Em relação aos resultados do presente estudo, Vilela et al. (1996) e Alvim et al. (1997), fertilizando a pastagem de coast-cross com 350 e $380 \mathrm{~kg} / \mathrm{ha} /$ ano de $\mathrm{N}$, registraram teores semelhantes de proteína bruta e superiores de digestibilidade in vitro da matéria seca.

Entre as fases da lactação, houve diferença $(\mathrm{P}<0,05)$ quanto à produção diária de leite nas três doses de $\mathrm{N}$ aplicadas na pastagem, sendo maior na primeira fase, e menor na terceira (Tabela 4). Essa diferença era esperada, pois é conseqüência natural do estádio de lactação dos animais. Entretanto, também pode estar associada com a quantidade de con-

Tabela 3. Consumo de matéria seca em kg/vaca/dia (concentrado e pasto) de vacas Holandesas em pastagem de coastcross, conforme a época do ano (condições climáticas) e de doses de nitrogênio aplicadas ${ }^{(1)}$

\begin{tabular}{|c|c|c|c|c|c|c|}
\hline \multirow[t]{3}{*}{ Mês } & \multicolumn{6}{|c|}{ Doses de N (kg/ha) } \\
\hline & \multicolumn{2}{|c|}{100} & \multicolumn{2}{|c|}{250} & \multicolumn{2}{|c|}{400} \\
\hline & Concentrado & Pasto & Concentrado & Pasto & Concentrado & Pasto \\
\hline & \multicolumn{6}{|c|}{ Chuva/calor } \\
\hline Fevereiro & 8,1 & 12,3 & 8,1 & 12,5 & 8,1 & 12,4 \\
\hline Março & 8,1 & 12,0 & 8,1 & 11,8 & 8,1 & 12,0 \\
\hline \multirow[t]{2}{*}{ Abril } & 8,1 & 11,8 & 8,1 & 12,0 & 8,1 & 12,2 \\
\hline & \multicolumn{6}{|c|}{ Irrigação/frio } \\
\hline Maio & 5,5 & 10,8 & 5,5 & 10,9 & 5,5 & 10,9 \\
\hline Junho & 5,5 & 10,5 & 5,5 & 10,5 & 5,5 & 10,7 \\
\hline Julho & 5,5 & 10,2 & 5,5 & 10,0 & 5,5 & 10,3 \\
\hline \multirow[t]{2}{*}{ Agosto } & 2,7 & 10,9 & 2,7 & 11,2 & 2,7 & 11,0 \\
\hline & \multicolumn{6}{|c|}{ Irrigação/calor } \\
\hline Setembro & 2,7 & 14,0 & 2,7 & 13,8 & 2,7 & 14,2 \\
\hline Outubro & 2,7 & 15,3 & 2,7 & 15,9 & 2,7 & 15,6 \\
\hline
\end{tabular}

${ }^{(1)}$ Média de dois períodos de avaliação, de 304 dias cada um.

Tabela 4. Produções de leite ( $\mathrm{kg} / \mathrm{vaca} / \mathrm{dia}$ e $\mathrm{kg} / \mathrm{lactação)} \mathrm{de} \mathrm{vacas} \mathrm{da} \mathrm{raça} \mathrm{Holandesa} \mathrm{em} \mathrm{pastagem} \mathrm{de} \mathrm{coast-cross,} \mathrm{em}$ razão de doses de nitrogênio ${ }^{(1)}$

\begin{tabular}{cccc}
\hline Fase da lactação (dias) & \multicolumn{3}{c}{ Doses de $\mathrm{N}(\mathrm{kg} / \mathrm{ha} / \mathrm{ano})$} \\
\cline { 2 - 4 } & 100 & 250 & 400 \\
\hline & & (kg/vaca/dia) & \\
1 a 100 & $20,8 \mathrm{aA}(2,9)$ & $21,1 \mathrm{aA}(2,4)$ & $21,4 \mathrm{aA}(2,7)$ \\
101 a 200 & $17,1 \mathrm{aB}(2,2)$ & $16,9 \mathrm{aB}(2,0)$ & $17,6 \mathrm{aB}(2,3)$ \\
201 a 304 & $12,9 \mathrm{aC}(1,8)$ & $13,8 \mathrm{aC}(1,7)$ & $13,2 \mathrm{aC}(1,7)$ \\
\hline Média & $16,9 \mathrm{a}(2,3)$ & $17,3 \mathrm{a}(2,1)$ & \\
\hline & & (kg/lactação) & $5.273 \mathrm{a}(502)$ \\
\hline
\end{tabular}

${ }^{(1)}$ Médias de 16 vacas por tratamento; oito por período de avaliação; os dados representam médias de dois períodos de avaliação, de 304 dias cada um; valores entre parêntesis correspondem ao erro-padrão da média; médias seguidas da mesma letra, minúscula na linha e maiúscula na coluna, não diferem entre si, pelo teste de Tukey a $5 \%$ de probabilidade. 
centrado oferecida aos animais, que na primeira fase da lactação correspondeu a $9 \mathrm{~kg} / \mathrm{vaca} /$ dia, na segunda foi de $6 \mathrm{~kg} / \mathrm{vaca} / \mathrm{dia}$, e na última, foi de $3 \mathrm{~kg} / \mathrm{vaca} /$ dia.) Não houve diferença $(\mathrm{P}>0,05)$ na média da produção de leite referente a todo o período experimental, em kg/vaca/dia, nem sobre a produção total de leite por lactação (Tabela 4). Resultados semelhantes foram obtidos por Vilela et al. (1996), apesar de os animais deste experimento terem recebido maior quantidade de concentrado. No entanto, as produções de leite por animal foram inferiores às alcançadas por Alvim et al. (1997), talvez pelo fato de grande parte do período experimental deste trabalho ter correspondido à época da seca, quando a qualidade da forragem disponível na pastagem foi inferior (Tabela 2). A produção de leite registrada em Cuba por Martinez et al. (1980), com animais da raça Holandesa em pastagem de coast-cross, foi inferior às alcançadas no presente trabalho.

A ocorrência de baixas temperaturas e pouca luminosidade durante o período de maio a agosto, além de ter limitado a qualidade da forragem, também limitou o crescimento do coast-cross. Assim, nas três doses de $\mathrm{N}$ aplicadas, registrou-se, durante $\mathrm{o}$ período da seca, menor disponibilidade de forragem na pastagem, o que fez reduzir o consumo de maté- ria seca, nesta época do ano, em relação à época das chuvas (Tabela 3 ), sem contudo atingir valores que pudessem comprometer a produção de leite, segundo o National Research Council (1987). Como foi registrada semelhança entre tratamentos para teor de proteína bruta e digestibilidade in vitro da matéria seca, não se observou diferença entre tratamentos para consumo de matéria seca proveniente do pasto, tanto na época da seca como nas chuvas, apesar de a disponibilidade de forragem ter sido menor na dose de $\mathrm{N}$ de $100 \mathrm{~kg} / \mathrm{ha} /$ ano (Tabela 1).

Para manter a pressão de pastejo ao redor de $6 \%$, as taxas de lotação da pastagem na época da seca foram inferiores $(\mathrm{P}<0,05)$ às da época das chuvas. Vilela et al. (1996) e Alvim et al. (1997) registraram variações na taxa de lotação ao longo do ano, que, em média, corresponderam a três vacas/ha, na época da seca, e seis vacas/ha, na época das chuvas. No presente trabalho, na média do período experimental, a taxa de lotação na pastagem foi menor $(\mathrm{P}<0,05)$, quando foram aplicados $100 \mathrm{~kg} / \mathrm{ha} /$ ano de $\mathrm{N}$, havendo semelhança $(\mathrm{P}>0,05)$ nas outras duas doses desse nutriente (Tabela 5). A taxa de lotação da pastagem foi mais elevada $(\mathrm{P}<0,05)$ no período correspondente às avaliações da primeira fase da lactação do que nos períodos relativos às outras duas

Tabela 5. Taxa de lotação, produção de leite de vacas da raça Holandesa em pastagem de coast-cross, e eficiência de doses de nitrogênio aplicadas ${ }^{(1)}$.

\begin{tabular}{|c|c|c|c|}
\hline \multirow[t]{2}{*}{ Fase da lactação (dias) } & \multicolumn{3}{|c|}{ Doses de N (kg/ha/ano) } \\
\hline & 100 & 250 & 400 \\
\hline & \multicolumn{3}{|c|}{ Lotação (vacas/ha) } \\
\hline 1 a 100 & $6,2 \mathrm{bA}$ & $7,4 \mathrm{aA}$ & $7,4 \mathrm{aA}$ \\
\hline 101 a 200 & $4,3 \mathrm{bB}$ & $4,9 \mathrm{aB}$ & $5,0 \mathrm{aB}$ \\
\hline 201 a 304 & $4,6 \mathrm{bB}$ & $5,2 \mathrm{aB}$ & $5,4 \mathrm{aB}$ \\
\hline \multirow[t]{2}{*}{ Média } & $5,0 \mathrm{~b}$ & $5,8 \mathrm{a}$ & $5,9 \mathrm{a}$ \\
\hline & \multicolumn{3}{|c|}{ Produção de leite $(\mathrm{kg} / \mathrm{ha} / \mathrm{dia})$} \\
\hline 1 a 100 & $129,0 \mathrm{bA}(12,4)$ & $156,1 \mathrm{aA}(16,3)$ & $158,4 \mathrm{aA}(15,2)$ \\
\hline 101 a 200 & $73,5 \mathrm{bB}(8,3)$ & $82,8 \mathrm{aB}(7,6)$ & $88,0 \mathrm{aB}(9,4)$ \\
\hline 201 a 304 & $59,4 \mathrm{bB}(5,2)$ & $71,8 \mathrm{aB}(6,7)$ & $71,3 \mathrm{aB}(6,5)$ \\
\hline \multirow[t]{2}{*}{ Média } & $87,3 \mathrm{~b}(8,3)$ & $103,6 \mathrm{a}(8,0)$ & $105,9 \mathrm{a}(9,3)$ \\
\hline & \multicolumn{3}{|c|}{ Produção de leite $(\mathrm{kg} / \mathrm{ha} / 304$ dias) } \\
\hline \multirow[t]{2}{*}{ Média } & $26.539,0 \mathrm{~b}$ & $31.494,0 \mathrm{a}$ & $32.194,0 \mathrm{a}$ \\
\hline & \multicolumn{3}{|c|}{ Eficiência (kg de leite/kg de N) } \\
\hline Média & 265,4 & 123,5 & 80,5 \\
\hline
\end{tabular}


fases. Provavelmente isso ocorreu em razão da época do ano e da quantidade de concentrado que os animais receberam em cada fase. Nos primeiros 100 dias de avaliação, ocorridos durante a época das chuvas e de alta temperatura (janeiro a abril), o crescimento do coast-cross foi favorecido e os animais também receberam a maior quantidade de concentrado (9 kg/vaca/dia). Nas demais fases, além da forragem da pastagem de coast-cross se apresentar com qualidade inferior à da primeira fase, os animais também receberam menor quantidade de concentrado. Tais resultados demonstram a impossibilidade de se alcançar, na Região Sudeste, altas produções de forragem ao longo de todo o ano, principalmente quando é usada menor dose de N. Este fato ficou também evidenciado por Alvim et al. (1998), que, na época da seca, registraram crescimento reduzido do coastcross manejado sob corte, especialmente quando foram aplicadas baixas doses de N. Nessas condições, esses autores mostraram, ainda, que, na aplicação de até $250 \mathrm{~kg} / \mathrm{ha} /$ ano de $\mathrm{N}$, a persistência dessa forrageira foi comprometida pela competição com plantas invasoras. Portanto, o equilíbrio na taxa de lotação da pastagem ao longo de todo o ano dependerá de suplementação volumosa dos animais, durante a época de menor crescimento da forrageira.

Apesar de não ter sido observada diferença entre produções individuais de leite, a diferença registrada entre tratamentos para taxa de lotação da pastagem resultou em diferença $(\mathrm{P}<0,05)$ entre tratamentos para produções de leite por área. As taxas de lotação alcançadas, associadas com as produções médias individuais de leite, resultaram, durante todo o período experimental, em maiores $(\mathrm{P}<0,05)$ produções de leite por área, ao serem aplicados $250 \mathrm{e}$ $400 \mathrm{~kg} / \mathrm{ha} / \mathrm{ano}$ de N, não havendo diferença $(\mathrm{P}>0,05)$ entre as produções desses dois tratamentos (Tabela 5).

As produções de leite por área, acumuladas nos 304 dias de avaliação, foram elevadas, sendo de $26.539,31.494$ e $32.194 \mathrm{~kg} / \mathrm{ha}$, respectivamente quando a adubação nitrogenada da pastagem de coastcross foi de 100, 250 e $400 \mathrm{~kg} / \mathrm{ha} /$ ano de N (Tabela 5). As produções anuais de leite alcançadas por Alvim et al. (1997), com vacas também em pastagem de coast-cross, foram de 28.000 e $38.000 \mathrm{~kg} / \mathrm{ha}$, dife- rença que se deveu ao fornecimento para os animais de 3 e $6 \mathrm{~kg} / \mathrm{vaca} /$ dia de concentrado, respectivamente.

A eficiência do $\mathrm{N}$ aplicado na pastagem de coastcross (quantidade de leite produzido por $\mathrm{kg}$ de $\mathrm{N}$ aplicado) foi considerada elevada. No entanto, os resultados mostraram que a eficiência diminuiu com o aumento das doses de $\mathrm{N}$, correspondendo à produção de leite de $265,4,123,5$ e 80,5 kg de leite produzidos por $\mathrm{kg}$ de $\mathrm{N}$ aplicado, respectivamente, nas dosagens de 100, 250 e $400 \mathrm{~kg} / \mathrm{ha} /$ ano de N (Tabela 5). Alvim et al. (1997), aplicando $380 \mathrm{~kg} / \mathrm{ha} / \mathrm{ano}$ de $\mathrm{N}$ em pastagem de coast-cross e variando a quantidade de concentrado fornecido aos animais em pastejo, 3 e $6 \mathrm{~kg} / \mathrm{vaca} / \mathrm{dia}$, alcançaram produções de 74,8 e $99,9 \mathrm{~kg}$ de leite por $\mathrm{kg}$ de $\mathrm{N}$ aplicado, respectivamente.

A aplicação de $100 \mathrm{~kg} / \mathrm{ha} / \mathrm{ano}$ de $\mathrm{N}$ foi a de menor custo, enquanto a dose de $400 \mathrm{~kg} / \mathrm{ha} / \mathrm{ano}$ foi a de custo mais elevado. Por outro lado, a receita obtida com a venda do leite foi menor na dose de $100 \mathrm{~kg} / \mathrm{ha} / \mathrm{ano}$ de $\mathrm{N}$ e maior na dose de $400 \mathrm{~kg} / \mathrm{ha} / \mathrm{ano}$ Com isso, a diferença entre o valor recebido com a venda do leite e o custo do $\mathrm{N}$ resultou numa margem bruta menor quando se aplicaram $100 \mathrm{~kg} / \mathrm{ha} /$ ano de $\mathrm{N}$, com valores próximos para as outras doses avaliadas (Tabela 6). Esses resultados mostram que o custo da adubação nitrogenada se torna baixo, quando é aplicado em forrageiras que apresentam elevado potencial de produção e quando

Tabela 6. Valor recebido com a venda do leite, custo da adubação nitrogenada e margem bruta ( $\mathrm{R} \$)$, em razão de doses de nitrogênio aplicadas em pastagem de coast-cross, pastejada por vacas da raça Holandesa em lactação.

\begin{tabular}{lrrr}
\hline Variável & \multicolumn{3}{c}{ Doses de N (kg/ha/ano) } \\
\cline { 2 - 4 } & \multicolumn{1}{c}{100} & \multicolumn{1}{c}{250} & \multicolumn{1}{c}{400} \\
\hline Venda do leite produzido $^{(1)}$ & $7.157,20$ & $8.677,38$ & $8.997,90$ \\
Custo do N aplicado $^{(2)}$ & 140,25 & 346,50 & 552,75 \\
Margem bruta & $7.016,95$ & $8.330,88$ & $8.445,25$ \\
\hline
\end{tabular}

(1) Valor do quilograma de leite B vendido, igual a $\mathrm{R} \$ 0,29$, em abril de 1999. (2)Preço do quilograma de N, como sulfato de amônio, igual a $\mathrm{R} \$ 1,65$, em abril de 1999; consideram-se aplicações de 85,210 e $335 \mathrm{~kg} / \mathrm{ha}$ de N em 304 dias (período experimental), respectivamente nas doses de 100 , 250 e $400 \mathrm{~kg} / \mathrm{ha} / \mathrm{ano}$. 
manejadas de forma adequada. Assim, nas condições edafoclimáticas semelhantes às deste experimento, não foi necessário aplicar mais que $250 \mathrm{~kg} / \mathrm{ha} / \mathrm{ano}$ de $\mathrm{N}$ em pastagem de coast-cross, pois nessa dose atingiu-se a maior produção de leite por área, sem prejuízo para a produção diária por animal, e alcançando-se a maior margem bruta.

\section{Conclusões}

1. Aplicações de 100, 250 e $400 \mathrm{~kg} / \mathrm{ha} / \mathrm{ano}$ de $\mathrm{N}$ não interferem na produção individual de leite de vacas da raça Holandesa.

2. A dose de $250 \mathrm{~kg} / \mathrm{ha} /$ ano de $\mathrm{N}$ maximiza a taxa de lotação da pastagem e a produção de leite por área, e resulta em maior retorno econômico por unidade de área.

3. A dose de $100 \mathrm{~kg} / \mathrm{ha} /$ ano de $\mathrm{N}$ resulta em maior produção de leite por quilograma de $\mathrm{N}$ aplicado na pastagem de coast-cross.

\section{Referências}

ALVIM, M. J.; VILELA, D.; LOPES, R. S. Efeitos de dois níveis de concentrado sobre a produção de leite de vacas da raça Holandesa em pastagem de coast-cross (Cynodon dactylon (L.) Pers.). Revista Brasileira de Zootecnia, Viçosa, v. 26, n. 5, p. 967-975, set./out. 1997

ALVIM, M. J.; XAVIER, D. F.; BOTREL, M. A.; MARTINS, C. E. Resposta do coast-cross (Cynodon dactylon (L.) Pers.) a diferentes doses de nitrogênio e intervalos de cortes. Revista Brasileira de Zootecnia, Viçosa, v. 27, n. 5, p. 833-840, set./out. 1998.

BOTREL, M. A.; ALVIM, M. J.; XAVIER, D. F. Avaliação de forrageiras em duas regiões do Campo das Vertentes de Minas Gerais. Revista da Sociedade Brasileira de Zootecnia, Viçosa, v. 23, n. 2, p. 189-196, mar./abr. 1994

COWAN, R. T. Responses to concentrate feeding. In HIGH PRODUCTION PER COW SEMINAR, 1990, Sidney. Proceedings... Sidney : Queensland Department of Primary Industries, 1990. p. 14-26.
DAVISON, T. M. The milk production potential of forage-concentrate systems in Queensland. In: HIGH PRODUCTION PER COW SEMINAR, 1990, Sidney. Proceedings... Sidney : Queensland Department of Primary Industries, 1990. p. 1-13.

HERRERA, R. S. La calidad de los pastos. In: INSTITUTO DE CIENCIAANIMAL (Habana, Cuba). Los pastos en Cuba. Havana, 1983. t. 2, p. 59-115.

HERRERA, R. S.; RAMOS, N.; HERNANDEZ, Y. Respuesta de la bermuda cruzada a la fertilización nitrogenada y edad de rebrote. V. Rendimientos de materia seca, hojas, proteína bruta e eficiencia de utilización del nitrógeno. Revista Cubana de Ciencia Agrícola, Havana, v. 20 , n. 2 , p. $180-189,1986$.

INFANTE, F. Nuevas consideraciones sobre el balance alimentario. In: INSTITUTO DE CIENCIA ANIMAL (Havana, Cuba). Los pastos en Cuba. Havana, 1983. t. 2 , p. $565-581$

MARTINEZ, R. O.; RUIZ, R. H.; HERRERA, R. Milk production of cows grazing coast-cross $\mathrm{n}-1$ Bermuda grass (Cynodon dactylon). I. Different concentrate supplementation levels. Revista Cubana de Ciencia Agrícola, Havana, v. 14, n. 2, p. 225-232, 1980.

NATIONAL RESEARCH COUNCIL. (Washington, DC) Predicting feed intake of food-producing animals. Washington, DC : National Academy Press, 1987. 85 p.

STOBBS, T. H. Milk production per cow and per hectare from tropical pastures. (milk production from tropical pastures). In: SEMINARIO INTERNACIONAL DE GANADERIA TROPICAL Y PRODUCCIÓN DE FORRAJES, 1976, México. Memoria... México : Secretaria de Agricultura e Ganaderia/Banco del México, 1976. p. $129-146$

TRUJILLO, R. Potencial y utilización de los pastos tropicales para la producción de leche. In: INSTITUTO DE CIENCIA ANIMAL (Havana, Cuba). Los pastos en Cuba. Havana, 1983. t. 2, p. 247-298.

VILELA, D.; ALVIM, M. J.; CAMPOS, O. F.; REZENDE, J. C. Produção de leite de vacas holandesas em confinamento e em pastagem de coast-cross. Revista Brasileira de Zootecnia, Viçosa, v. 25, n. 6, p. 1228-1244, nov./ dez. 1996. 